\title{
Toxoplasma gondii In Morocco And Palestine: General Review
}

\author{
Zuhair Dardona, Safa Ben Alla, Mohamed Hafidi, Ali Boumezzough, and Samia Boussaa
}

\section{ABSTRACT}

Toxoplasma gondii is a ubiquitous intracellular parasite, which is commonly known to infect all warm-blooded animals. Almost $30 \%$ of the world's human population is infected with this parasite, though the infection varies depending on the region and ethnic group. Also, almost half of pregnant women in Morocco and one-third in Palestine have been infected with toxoplasmosis. Several studies have been conducted in order to estimate the prevalence of this parasite among pregnant women in Morocco and Palestine. However, studies revolving around the occurrence of this parasite among livestock and the environment in Palestine and Morocco are inadequate. This review will shed light on the underlying risk factors associated with the prevalence of this parasite by drawing on a comparison between the occurrence of toxoplasmosis in two different countries. It also intends on increasing the awareness and knowledge regarding this parasite among the general population. Nonetheless, Congenital toxoplasmosis as well as the seroprevalence of Toxoplasmosis among women who have undergone abortion still need to be studied further, particularly in Morocco.

Keywords: Toxoplasma gondii, Toxoplasmosis, Prevalence, Morocco, Palestine, Risk factors.

\section{INTRODUCTION}

Toxoplasma gondii is an intra-cellular parasite that can infect all warm-blooded animals. It was first discovered in Tunisia in 1908 by the French parasitologists Nicolle and Manceaux while they were investigating a reservoir host for Leishmania in a desert rodent named Ctenodactylus gondii (common gondii) [1]. Much later, precisely after six decades (1968-1970), Toxoplasma gondii's life cycle was first described. "Toxon" is a Greek term referring to something that is "crescent shaped", which describes one of the three infectious stages of this parasite, the tachyzoite stage. "Plasma" is also a Greek word meaning "creature". Given this, the name of this parasite stems from its tachyzoite shape. Carnivorism was recorded as a mode of transmission for the first time in 1937. This was confirmed in 1965 where a high occurrence of $T$. gondii infections were witnessed in a hospital as a diet consisting of raw meat was given therapeutically [1], [2]. Despite being a single species in this genus, $T$. gondii compensates for what it lacks in other members of species with its number of hosts; it can infect all mammals and birds [3].T. gondii is characterized by a threestage life cycle[4]. Sexual reproduction occurs exclusively in the intestine of the feline, a definite host, resulting in formation of oocysts, and are shed in the feces (Fig. 1).Oocysts become infective after sporulation in the environment, where they are distributed by wind and water. T. gondii oocysts are resistant to harsh environmental, physical and chemical conditions and can remain infectious
Published Online: November 28,2020

ISSN: 2684-5199

DOI: $10.24018 /$ ejbio.2020.1.6.118

Zuhair Dardona*

Microbial Biotechnologies, Agrosciences and Environment Laboratory (BioMAgE), Faculty of Sciences Semlalia, Cadi Ayyad University, Morocco.

(e-mail: zuhair.dardona@gmail.com)

Safa Ben Alla

(e-mail: benalla.bio@gmail.com ) Mohamed Hafidi

(e-mail: hafidi.ucam@gmail.com) Ali Boumezzough

(e-mail: aboumezzough@gmail.com)

Samia Boussaa

(e-mail: samiaboussaa@gmail.com)

ISPITS-Higher Institute of Nursing and Health Techniques, Ministry of Health, Morocco.

*Corresponding Author

as long as they are in the environment for as many years as possible [5]. Ingestion of sporulated oocysts by intermediate hosts leads to liberation of sporozoites, which penetrate the intestinal epithelium and spread into tachyzoites. This is followed by dissemination of tachyzoites via body fluids and their massive and fast asexual replication in nucleated cells of the host [4], [5]. This stage of infection is characterized by a strong inflammatory response and tissue destruction, which may result in clinical manifestations of the disease. After further progression in the host's immune response, replication decays and the new called bradyzoites settle in the host's cells of the retina, brain, skeletal and heart muscles[5]. Through formation of tissue cysts, the parasite can evade the immune system and survive a lifetime within the host. Toxoplasmosis can horizontally be acquired by ingestion of oocysts either through consumption of contaminated food (vegetables, fruits, and water), or by smear infection through gardening or direct contact to cat feces. Oral-alimentary transmission can also occur by consumption of raw or undercooked meat containing highly infectious tissue cysts[6]. In addition, it is argued that handling raw meat alone can inherit a risk for infection[6], [7]. Tachyzoites are the causative agents of vertically acquired congenital toxoplasmosis (CT), but they are generally believed to play a minor role in horizontal transmission. However, due to their presence in body fluids, a risk for transmission by organ transplantations or by consumption of raw milk cannot be excluded [7]. 


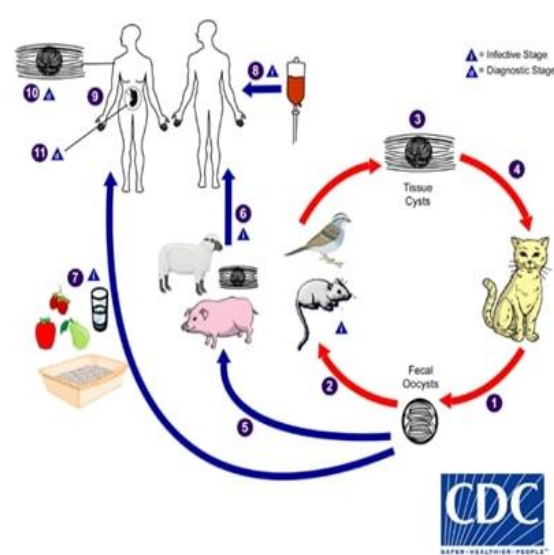

Fig. 1. Toxoplasma gondii life cycle [53].

As also seen by the seroprevalence data (Fig. 2), the relative importance of different risk factors for acquiring human toxoplasmosis varies significantly depending on the geographical region or ethnic group as well as the epidemiological significance of different transmission routes, though it's still largely unknown [7]. In 2011, $50 \%$ of $T$. gondii infections in the United States were foodborne [7]. Moreover, several studies have identified the consumption of raw or undercooked meat as the most important risk factor for pregnant women in Europe [8]; however, there are some variations observed in the type of meat associated with the greatest risk [6], [9], [10].

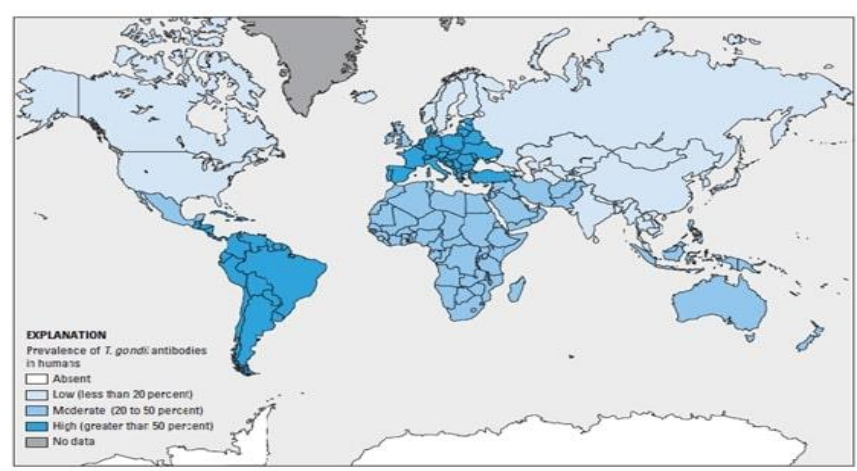

Fig. 2. Geographical distribution of human Toxoplasmosis in the world [16].

\section{Public Health CONCERNS AND Human TOXOPLASMOSIS}

Toxoplasmosis is one of the most common parasitic zoonosis worldwide. It is estimated that approximately $30 \%$ of the human population (Fig. 2) is infected with this parasite [5]. Primary infections during pregnancy are the most relevant for public health concerns. Depending on the trimester of pregnancy, congenital infection of the unborn child may result in abortion, stillbirth, hydrocephalus, retinochoroiditis, intracranial calcifications, hydrocephalus, or psychometric and neurological disabilities[11],[12]. Although, most postnatal acquired infections remain asymptomatic or result in mild flu-like symptoms. Ocular toxoplasmosis in immunocompetent people seems to manifest more often than previously thought[6], [13]. Severe clinical manifestations and reactivation of latent infections can occur under immunocompromising conditions (e.g.
HIV/AIDS, transplantation patients) and hence resulting in life-threatening encephalitis or the central nervous system (CNS) disease in patients with AIDS [13]. Mainly, due to fetal loss and sequelae such as chorioretinitis, a high disease burden was determined based on DALY in the USA and the Netherlands, which ranked $T$. gondii among the two most harmful foodborne pathogens[14], [15]. A ranking of global importance of 24 food-borne parasites by socioeconomic and trade impact placed $T$. gondii in the fourth place [16]. According to WHO, [17] there is a million new cases of toxoplasmosis in the European region as a result of food contamination, annually.

\section{TOXOPLASMa GoNDII IN PALESTINE}

\section{A. Toxoplasma gondii in Humans}

Even though this parasite was discovered in 1908 by the two French parasitologists Maanceaux and Nicoile in a rodent in Tunisia [1], the research studies surrounding this particular topic regarding Toxoplasma gondii was only carried out recently in Palestine, and in fact, it has been long overdue. This late response in implementing such studies in Palestine could be attributed to reasons such as delayed cultural awareness, as well as the low interest and poor funding of scientific research throughout the Arabic region and particularly in the Palestinian Territories. The first study investigating Toxoplasma in Palestine was published after a century since it was first discovered. This study was carried out by Najem., K. I. and Al Amleh., in the city of Hebron and was published in 2009. The objective of the study was to investigate the seroprevalence of $T$. gondii antibodies both $\mathrm{IgG}$ and $\operatorname{IgM}$ among 204 pregnant women through the use of the ELISA technique, despite the fact that the study was carried out during 2005 and published on a much later date, 2009. Nonetheless, the results of this study revealed that there was a high seroprevalence of Toxoplasma among the 204 samples, whereby $27.9 \%$ and $17.6 \%$ of $T$. gondii antibodies were reported, $\operatorname{IgG}$ and $\operatorname{IgM}$, respectively. Upon a careful perusal of the results obtained by this study, it was discerned that the rate of infection increased as age increased. Also, seroprevalence of $T$. gondii was reported higher in rural areas given that $36.85 \%$ IgG of samples were reported in rural areas in comparison to $21.4 \%$ in urban areas. This study also highlighted some of the most important risk factors associated with the increase and spread of the infection, which were direct contact with soil, drinking rain water, eating raw or unwashed vegetables, ingesting raw or undercooked meat and contact with cats. Moreover, the study revealed that $37.3 \%$ of women reported previous miscarriages, though it was not reported to have a statistically significant relationship with Toxoplasma infections [18]. Not only does the aforementioned study hold precedence as it was the first ever to be carried out in investigating Toxoplasma; it is also quite inclusive and draws on a comprehensive report. The study sheds light on the seroprevalence of Toxoplasma and unveils the various risk factors of toxoplasmosis. When trying to further understand the related risk factors contributing to the prevalence of $T$. gondii and particularly the fact that ingestion of raw or undercooked meat and direct contact 
pose less of a risk factor than ingestion of raw vegetables, contact with soil and drinking unfiltered water, we should consider the overall picture. This observation is justified given that the behavior and cultural norms of the inhabitants where the study was implemented prevent or do not encourage ingestion of raw meat, let alone that having cats as pets or even petting stray cats is uncommon. Within the same year, AL-Hindi and Lubbad implemented a similar study in Gaza, which focused on detection of seroprevalence in women who have undergone abortion. The study was the first in Gaza as well as the first of its kind to study this certain demographic in Palestine. Aside from studying this focus group, the study also evaluated the relationship between breeding animals and the occurrence of Toxoplasma. Al-Hindi's study used 312 blood samples, which were collected from aborted women to detect Toxoplasma antibodies using the ELISA technique. The results of the study revealed that seroprevalence of $\mathrm{IgG}$ and IgM were $17.9 \%$ and $12.8 \%$, respectively. The ages of the participants ranged between 16 and 40 years, and the geographical distribution from where the samples were collected was as follows; $69.2 \%$ from Gaza city and $30.8 \%$ from the surrounding suburbs. Among the participating women $59.0 \%$ of them had completed secondary education and $33.3 \%$ of them have domestic animals as pets or are animal breeders. Nevertheless, the study suggested that Toxoplasma may indeed pose as a risk factor in influencing miscarriages among pregnant women within the study's subject area. The study also has recommended that pregnant women should frequently and routinely undergo Toxoplasma antibodies tests [19]. Through careful assessment of the study's results, we can safely conclude that seroprevalence of Toxoplasma among women who have had abortion is not nil, rather it is indeed present and with a surprisingly high percentage rate. However, the argument of whether toxoplasmosis is the main source or only direct reason of abortion among this demographic remains as a matter to be examined further and determined. The fact that at least $59.0 \%$ of the women infected had finished secondary education while only $14.1 \%$ had completed university level education highlights a crucial point, which is that most of the target group suffer from low education. Since $33.3 \%$ of the target women are domestic animal owners or breeders, the point that this could be a contributing factor to transmission of Toxoplasma among aborted women should be considered. Given this, it is clear that the general demographic of the target group who are vulnerable to the risk factors discussed above such as low educational level, residing in rural areas, direct contact with cats and low economic level are sufficiently and effectively represented by the study [20]. In addition, the effect of transmitting Toxoplasmosis to humans is more likely to occur through domestic cat breeders and owners rather than stray cats. In other words, breeding of domestic cats contributes more to the spread of toxoplasmosis within our society than stray cats. This is due to domestic cats having a higher ability to form and proliferateoocysts, which is the environmental infectious stage of Toxoplasma, than stray cats. This is logically consistent with and confirmed by the results obtained from the study. Al-Hindi also published another similar study during 2010, which studied the relationship between the prevalence of toxoplasma as well as other pathogens with miscarriage cases in Gaza city. For the objective of the study, 1954 samples were collected from vitro fertilization clinics in Gaza of women suffering infertility and abortion. The samples were collected between 2000 and 2005. Al-Hindi's previous study suggested that Toxoplasma served as a public health concern among pregnant women and could be considered to be among other factors that cause abortion [21]. In this study, the ELSA technique was used and $7.9 \%$ of the target group reported Toxoplasma antibodies. In line with similar studies carried out for the purpose of detecting Toxoplasma antibodies in pregnant women in Gaza, Al-Jarousha, A. M. was published in 2012. The study documented the seroprevalence of Toxoplasma antibodies in pregnant women from different socioeconomic classes, where blood samples were collected from 255 pregnant women. Nevertheless, the study mentioned some risk factors such as low socioeconomic levels, residing in rural areas, direct contact with soil, and owning cats as pets. Again, using the ELISA technique, the results of the study discovered that prevalence of Toxoplasma antibodies among the target group were $30.9 \%$ IgG and 5.8\% IgM [22]. On the other hand, another study was carried out in Al Najah National University in Nablus, Palestine, in order to evaluate females' health awareness of Toxoplasma. The target group, which consisted of 976 undergraduate female students was handed a questionnaire survey where the average age of the group was between 18 and 23 years. The results of this rare study discovered that half of the respondents have not heard about Toxoplasma before, while more than $93.7 \%$ of them have never been tested for Toxoplasma. However, the majority of the group indicated that they exercise hygienic practices including washing their hands, regularly cleaning their cat's litter box, and avoid consumption of undercooked raw meat [23]. Although this group and particularly the general demographic it represents are considered to be most affected by this disease, the study illustrated that this female group yet had a shockingly low health awareness level and lack of knowledge about Toxoplasma. Therefore, more efforts must be geared towards promoting awareness regarding Toxoplasma among females. A similar study was one of the most recent studies to be implemented in Gaza, Palestine, which was published during 2019. The study collected 245 samples from female university students with ages ranging between 18 and 25 years. The blood samples were tested using the ELISA technique in order to detect Toxoplasma antibodies IgG and $\operatorname{IgM}$ whereby the results revealed a high seroprevalence level of Toxoplasma among them with $40.4 \%$ [24]. While (Fig.3) illustrates the geographical distribution of Toxoplasmosis among tested pregnant women in Palestine. 


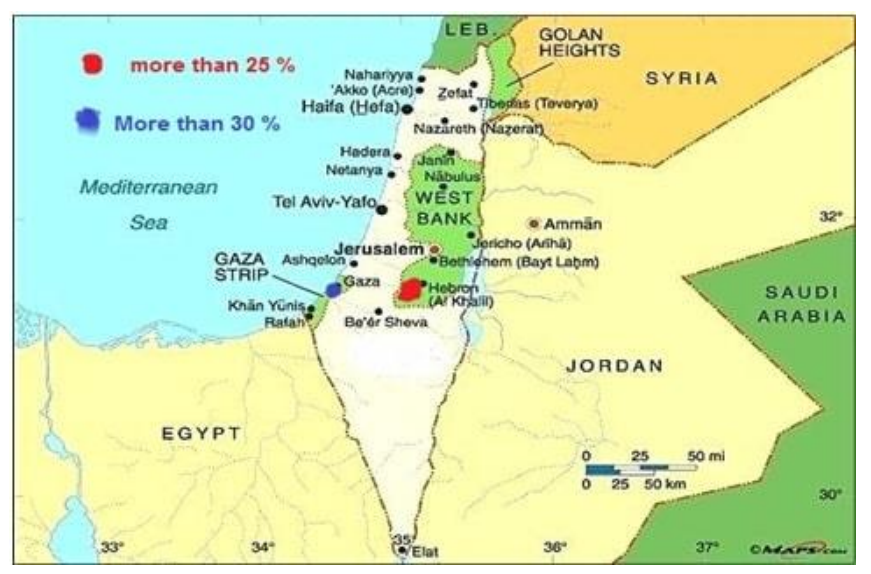

Fig. 3. The geographical distribution of Toxoplasmosis among tested pregnant women in Palestine, (Data from the results which mentioned in this review other regions "No Data").

\section{B. Toxoplasma gondii in Animals}

Five years after the first study of Toxoplasma in humans was published in Palestine, Othman and Al Zuhair published their first study investigating toxoplasmosis in animals. The objective of the study focused on assessing the prevalence of Toxoplasma in goat herds in two of Palestine's northern cities, Jenin and Tulkarm. Among the two cities, 14 goat herds were examined in order to complete the objective of the study. From January to December of 2011, the authors collected 151 goat blood samples and following this, they were tested using the ELISA technique in order to detect Toxoplasma antibodies. Overall and taking into consideration the two cities combined, $13.4 \%$ of the tested goats were infected with Toxoplasma. In Jenin, $17.4 \%$ of the goats were infected, while a lower infection level was reported in goats herded in Tulkarm, $7.69 \%$. According to the researchers' interpretation, this difference could be attributed to the fact that the area designated for grazing animals in Jenin was bigger than that of Tulkarm's. Moreover, the number of sheep herds in Jenin was also more than in Tulkarm. Meanwhile, various reasons were suggested in order to explain the occurrence of Toxoplasma in goats, some of which included the poor conditions of storages designed to store goat feed stocks as well as insufficient veterinary care. Due to the presence of rodents, cats and dogs in these storage places, they are hence deemed unsuitable. In turn, this is considered to be a major contributing factor and particularly, cats, in the spread of Toxoplasma in goats [25].Similarly, another study was published during 2017 with a similar objective to the previously mentioned study, which is to detect the prevalence of Toxoplasma antibodies in sheep. Though, it was carried out and performed in a different region of Northern Palestine, specifically the Jordanian Valley. The results discovered that seroprevalence represented $20.5 \%$ out of the 2479 blood samples collected from sheep. Moreover, the ELISA technique was the method used to test those blood samples. The main conclusive point drawn by this study was that milk and its derivatives are considered to be a potential risk factor of toxoplasmosis [26]. During 2019, an exceptional study was published, which focused on detection of Toxoplasma occurrence and other intestinal parasites in stray cats in the Governorate of Kahnyounis, Gaza Strip, Palestine. The study collected fecal samples of
83 cats, which were examined by wet mount and flotation for $T$. gondii oocyst detection and the study found $T$. gondii in 5 of the samples, $5.4 \%$ [27]. Similarly, another study carried out in Gaza as well examined many domestic animals. For the purpose of the study, 60 blood samples were collected from cows, sheep and chickens and were tested using the latex agglutination technique. A high seroprevalence of Toxoplasma level in cows, sheep and chickens was in fact reported as illustrated by the following results, $28.3 \%, 33.3 \%, 46.7 \%$, respectively [24].

\section{Toxoplasma gondii in Food and Environment}

Despite the early discovery of Toxoplasma, there has been a lack of studies surrounding the occurrence of Toxoplasma in consumable food and environmental elements in Palestine. As a result, this research field remains an opaque topic. Nonetheless, few studies investigating the contamination of parasites in fresh vegetables and soil were conducted. A study was conducted by Al-Shawa and Mwafy whereby 216 vegetable samples were examined. Even though $T$. gondii was not among the detected parasites, a high level of parasite contamination was recorded in this sample size, specifically $27.0 \%$ [28]. Along the lines of a similar study, Al-Hindi et al. published a study in which the results reported did not detect $T$. gondii among the various parasites contaminating vegetables. However, out of the 320 vegetable samples collected, the results revealed that 188 $(36.9 \%)$ of them were contaminated with parasites [29]. Meanwhile, another study published by Hilles et al. which focused on examining the contamination of Gaza's shorelines reported no detection of $T$. gondii among the detected parasites [30]. Moreover, a study investigating the occurrence of Toxoplasma oocysts in fresh leafy vegetables which frequently eaten raw by the local demographic in Gaza, was conducted by Dardona et al. in 2019 and published in 2020. Using both sheather's solution and PCR techniques, the study in fact detected an occurrence of oocysts in these vegetables. Among the 300 vegetable samples collected, which were examined from March to August of 2019, the occurrence of oocysts was reported to be $6.6 \%$. Intuitively, the conclusive point emphasized by this study was that ingestion of unwashed raw leafy vegetables is considered to be a potential risk factor for transmission of Toxoplasma to both humans and animals [31]. The following Table 1 summarizes the most important Toxoplasma studies conducted in Palestine.

\section{TOXOPLASMA GONDII IN MOROCCO}

\section{A. Toxoplasma gondii in Humans}

Contrary to the situation addressed in Palestine, Toxoplasma has been studied and investigated much earlier in Morocco. By the end of the 1960s, Morocco's first study evolving around Toxoplasma was published. This study sought to investigate the prevalence of Toxoplasma by testing 154 patients using the immunofluorescence antibody test (IFAT), and approximately reported $64.9 \%$ positive results [32]. One of the first conducted studies about Toxoplasma in Morocco was carried out by Mekouar in 1972 in three cities: Nador, Kenitra and Tetouan; and the 
detected seroprevalences were $34.03 \%, 37.7 \%$ and $42.0 \%$ respectively [33].

TABLE 1:THE MOST IMPORTANT TOXOPLASMA STUDIES CONDUCTED IN PALESTINE

\begin{tabular}{|c|c|c|c|c|c|c|}
\hline Target group & Sample type & City & Technique & +VE results & $\begin{array}{c}\text { Year of } \\
\text { publication }\end{array}$ & Reference \\
\hline $\begin{array}{l}\text { Pregnant } \\
\text { women }\end{array}$ & Blood & Hebron & ELISA & $\begin{array}{l}\text { IgG } 27.9 \% \\
\text { IgM } 17.6 \%\end{array}$ & 2009 & 18 \\
\hline $\begin{array}{l}\text { Aborted } \\
\text { women }\end{array}$ & Blood & Gaza & ELISA & $\begin{array}{l}\operatorname{IgG} 17.9 \% \\
\operatorname{IgM} 12.8 \%\end{array}$ & 2009 & 19 \\
\hline $\begin{array}{l}\text { Infertile } \\
\text { women }\end{array}$ & Blood & Gaza & ELISA & $\operatorname{IgM} 7.90 \%$ & 2010 & 21 \\
\hline $\begin{array}{l}\text { Pregnant } \\
\text { women }\end{array}$ & Blood & Gaza & ELISA & $\begin{array}{l}\text { IgG30.0\% } \\
\text { IgM5.8 \% }\end{array}$ & 2012 & 22 \\
\hline $\begin{array}{l}\text { University } \\
\text { females } \\
\text { students }\end{array}$ & Blood & Gaza & ELISA & $\begin{array}{l}\operatorname{IgG} 25.8 \% \\
\operatorname{IgM} 18.4 \%\end{array}$ & 2019 & 24 \\
\hline $\begin{array}{l}\text { Chickens, } \\
\text { Cows and } \\
\text { Sheep }\end{array}$ & Blood & Gaza & $\begin{array}{c}\text { Latex } \\
\text { agglutination }\end{array}$ & $\begin{array}{c}\text { Chickens } 28.3 \% \\
\text { Cows } 33.3 \% \\
\text { Sheep } 4 \% 6.7\end{array}$ & 2019 & 24 \\
\hline Goats & Blood & $\begin{array}{c}\text { Jenin } \\
\text { Tulkarem }\end{array}$ & ELISA & $\begin{array}{l}\text { Jenin } 17.4 \% \\
\text { Tulkarem7.69\% }\end{array}$ & 2014 & 25 \\
\hline Sheep & Blood & $\begin{array}{l}\text { Northern of } \\
\text { Palestine }\end{array}$ & ELISA & $20.5 \%$ & 2017 & 26 \\
\hline Stray cats & Feces & Khanyounis & $\begin{array}{l}\text { Wet mount } \\
\text { Flotation }\end{array}$ & $5.4 \%$ & 2019 & 27 \\
\hline Raw food & $\begin{array}{c}\text { Leafs of } \\
\text { Vegetables }\end{array}$ & Gaza & $\begin{array}{c}\text { Flotation } \\
\text { PCR }\end{array}$ & $\begin{array}{c}11.66 \% \\
6.6 \% \\
\end{array}$ & 2020 & 31 \\
\hline
\end{tabular}

Following this study, which served as a starting point for other researchers to carry on similar studies, another old study was performed during 1973. With the objective of also detecting the occurrence of Toxoplasma, the later study collected 1026 serum samples from Military personnel, schoolgirls and pregnant women in Rabat city. From this sample size, the results of the study recorded a seroprevalence of Toxoplasma of $27.4 \%$ [34]. This study was only focused on the city of Rabat, though other studies covering other Moroccan cities were also conducted. According to a study that has conducted a similar study in Rabat as well, Nador and Tetouan, 50.6\%, 43.3\% and $42.6 \%$ were recorded, respectively [35]. Late in 1983, Biava et $a l$, used indirect immunofluorescence and passive haemagglutination methods in order to detect Toxoplasma antibodies in 318 girls and women aged between (18-40) years old, the results uncovered that more than $30 \%$ of tested girls and women had Toxoplasma antibodies more than $10 \mathrm{IU} / \mathrm{ml}$ [36].Even though this is quite a dated study, it still shows that this disease has a clear history in Morocco and for a long time needs to be further examined. In order to evaluate the epidemiological status of Toxoplasma in Essaouira-Safi region of Morocco, a study in 2014, noticed that $52.0 \%$ of 416 pregnant women had not been tested for anti-Toxoplasma antibodies in their previous pregnancy, while $45.0 \%$ were positive for anti-Toxoplasma antibodies. According to this study, low awareness concerning Toxoplasma in addition to low levels of hygiene were the main risk factors for Toxoplasma infections [37]. In 2010, AL-Souissi Maternity of Rabat examined a sample of 368 pregnant women and whereby more than $44 \%$ of the sample reported seropositive for Toxoplasma antibodies. The institution concluded that the seroprevalence had increased significantly with age, while no significant difference was discerned in the prevalence of antibodies between rural and urban areas [38]. Other studies were performed in Rabat during 2007, 2009 and 2010. The results showed that more than $50 \%$ of 2456,1020 and 500 pregnant women were respectively seropositive for Toxoplasma [39], [40]. Many other studies were carried out in order to detect the seroprevalence of Toxoplasma in many other Moroccan cities. For instance, in Casablanca during 1984, the result discovered that $51.5 \%$ of 200 pregnant women were seropositive [39], [40]. In 2016, Akourim revealed that the seroprevalence of Toxoplasmosis in the city of Agadir was $47.33 \%$ [40]. During 2009, a previous study addressed the various risk factors associated with Toxoplasmosis among pregnant women in Morocco. It revealed that $57.0 \%$ of the respondents were illiterate, $47.0 \%$ did not have any knowledge regarding this disease. Meanwhile, almost half of the respondents had direct contact with cats and soil as well as had consumed under-cooked meat, and nearly $53.0 \%$ performed poor levels of hygiene practices [41]. Although the existence of HIV in Morocco is insignificant, it is still reported that $62.0 \%$ of these HIV patients are infected with Toxoplasmosis [52]. In light of this and only few years ago, specifically in 2017, another researcher conducted a study in order to evaluate the prevalence of Toxoplasma in Morocco. One of the researcher's main findings were that seroprevalence of Toxoplasma in pregnant women reached $51.0 \%$. Such a percentage rate reflects a high prevalence since more than half of pregnant women were reported to carry the infection. This gives rise to a serious public health concern as it addresses the high epidemiological status of Toxoplasma in Morocco. The researcher also went further to address the various common risk factors playing a major role in this high prevalence, some of which are direct contact to soil, low awareness and knowledge levels as well as low education levels among pregnant women in Morocco [40]. Correspondingly, another study was carried out in Rabat, which examined 1169 pregnant women and reported a similar rate reported by the previously mentioned study, $53.0 \%$ [42]. Moreover, a study was conducted in order to shed light on the given behavior, awareness and knowledge of women concerning Toxoplasmosis in the province of Essuira. The study revealed that among a sample size of 600 women, only 22 had tested for Toxoplasma antibodies, which represents an extremely low percentage rate, $3.6 \%$. 
As for the respondents who had good knowledge and awareness about this parasite, only $2.6 \%$ of the total sample size was reported. These two figures serve as serious indicators for the astonishingly low awareness about this parasite among women of this particular province, and possibly the nation as a whole. In addition, the study also indicated that direct contact to soil posed as the strongest risk factor for transmission of Toxoplasma followed by poor hygienic practices and handling of raw meat [43]. In order to also evaluate the prevalence of Toxoplasma, only this time, in the city of Fes, a study collected samples throughout 2010 to 2015 from asymptomatic patients who visited central laboratory in Hassan II University Hospital. Blood samples were tested using the ELISA technique and whereby the results revealed showed that $39.7 \%$ of the tested women were in fact infected with Toxoplasma. The study also mentioned that eating habits, contact with cats, inadequate sanitation and poor hygienic practices were the most common risk factors [44]. Although various cities and focus groups were covered through studies published by different researchers, more regions in Morocco as well as other target groups such as aborted and infertile women still need to be also investigated in order to sufficiently depict and discover the actual prevalence of Toxoplasma. Fig. 4 below illustrates the seroprevalences of Toxoplasma in Morocco.

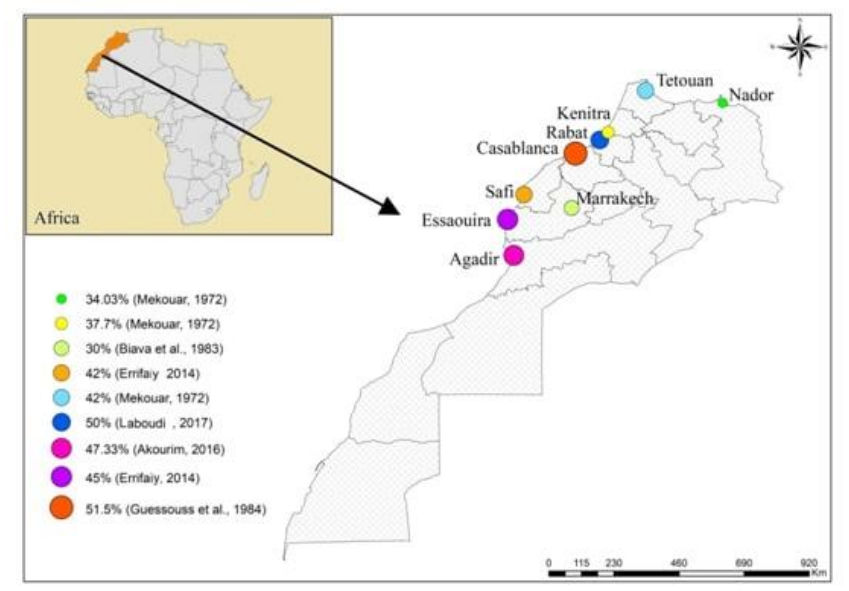

Fig .4. Geographical distribution of Toxoplasmosis in Morocco (Data from the mentioned studies, other regions "No Data" (Arc GIS 2019 ()).

\section{B. Toxoplasma gondii in Animals}

The livestock and poultry industries are known to be major industries in Morocco. Since Morocco is also considered to be one of the most prominent countries in raising livestock and poultry. Given the abundance of farmland and pastures, it was recorded that Morocco's livestock and poultry population was as follows 2,814,000 cattle, 17,078,000 sheep, 5,118,000 goats and 157,500,000 birds [45]. Only during 1990 did a study researching Toxoplasma in Animals was published. The study examined 23 herds of sheep suffering from recurrent abortion for pathogens including Toxoplasma that were likely to play a significant role in this phenomenon. For the objective of the study, blood samples were collected from aborted ewes and then tested using the ELISA technique. The results illustrated that Toxoplasma antibodies were detected in 9 out of the 23 herds, $39.0 \%$, while $30.0 \%$ of the total sample size reported positive for the infection [46]. Fourteen years after the first study of Toxoplasma in animals was published, which is a considerably long time, the second study was published in 2004. The objective of the second study was to detect the occurrence of cysts in cerebral tissue of 50 sheep after they were slaughtered for consumption. The samples were collected from a slaughterhouse and examined using the ELISA technique. Results of the study revealed that cysts of Toxoplasma were found in 15 out of the 50 sheep tested, $30.0 \%$. In order to confirm the reports of the previously mentioned study, the cerebral specimens were inoculated into mice, which was the first time and may be the last time in which mouse bioassay technique was used in Morocco for the detection of Toxoplasma [47]. Moreover, and this time in the city of Marrakesh, a similar study was also conducted whereby blood samples of 261 sheep were collected and examined through the ELISA technique. The results conveyed by the study's report discovered that Toxoplasma antibodies were detected in 27 samples, which represents $27.6 \%$ of the total sample size. Aside from this, the researcher also went further to illustrate that this rate of infection could be similar in other cities of Morocco, or possibly be applicable to Morocco in general. One of the study's most important recommendation was the need for including other domestic animals in similar studies in order to appropriately describe and present the epidemiological situation of Toxoplasma in consumable animal meat [48]. Consistent with the previous studies carried out on sheep and goats, another study was conducted in the Northern and Middle atlas of Morocco in order to detect the antiToxoplasma antibodies. The study used 202 sheep and 105 goats to be tested using the ELISA technique also. As per the results found by the study, antibodies were detected in $42(20.8 \%)$, and $9(8.5 \%)$, of sheep and goats, respectively [49]. The studies regarding the existence of this parasite in cattle and sheep are still so limited in Morocco. Though not the only study, but yet among the few studies, the study was carried out during 2017 in the northern city of Mekens and in the central city of Settat, in order to determine the prevalence of Toxoplasma in both of these cities, 226 cattle samples and 131 sheep samples were included. Upon collecting and testing the sera samples using a modified version of the direct agglutination test, the results revealed that the prevalence of anti-toxoplasma antibodies among cattle in the North and South were $7.5 \%$ and $8.5 \%$, respectively. On the other hand, among the sheep samples tested, $18 \%$ was reported in the city of Mekens while only $7.4 \%$ in the city of Settat [50]. As illustrated by the previously mentioned studies, the studies concerning animals were restricted to only sheep, goats, cattle, and ewes, are so limited. In other words, the variation of domestic animals was not sufficiently examined given that they were only centered around the animals mentioned above. Meanwhile, studies concerning poultry are completely absent. Hence, in order to clearly address the epidemiological situation concerning the prevalence of Toxoplasma in animals, it is strongly recommended that studies focusing on other domestic, stray and even wild animals and birds are to be pursued. Not to also mention, detection techniques are also limited to the use of only the ELISA technique. Molecular and genotyping, in addition to other serological methods remain not used or elusive. 


\section{Toxoplasma gondii in the Environment}

In a rare and exceptional study published only recently, during 2020 in Marrakech, focused on investigating the occurrence of Toxoplasma oocysts in the environment. Equipped with the bright field and UV microscope and 42 soil samples collected from 9 different sites located in various urban regions throughout Marrakech, the results of the study reported no contamination of oocysts in any of the samples [51]. Unfortunately, this is the only published study in Morocco concerning the prevalence of Toxoplasma in the environment and was overdue given that it emerged after nearly half a century from when the first study was ever conducted in Morocco regarding Toxoplasma. One of the surprising limitations of this study was that rural areas were not covered given that rural areas pose as one of the most common risk factors for toxoplasmosis as previously mentioned [20]. Moreover, there also does not seem to be any published study investigating the prevalence of Toxoplasma in soil from other regions of Morocco and other environmental elements such as water. Last but not least, it is also highly recommended that molecular detection of Toxoplasma should be performed in order to achieve more accuracy and confirmatory results. The following Table 2 summarizes the most important Toxoplasma studies conducted in Morocco.

TABLE 2: THE MOST IMPORTANT TOXOPLASMA STUDIES CONDUCTED IN MOROCCO

\begin{tabular}{|c|c|c|c|c|c|c|}
\hline $\begin{array}{l}\text { Target } \\
\text { group }\end{array}$ & $\begin{array}{c}\text { Sample } \\
\text { Type }\end{array}$ & City & Technique & $\begin{array}{c}+ \text { ve } \\
\text { Result } \\
\end{array}$ & $\begin{array}{c}\text { Year of } \\
\text { publication }\end{array}$ & Reference \\
\hline Patients & Blood & & IFAT & $64.9 \%$ & 1969 & 32 \\
\hline Women & Blood & Marrakech & $\begin{array}{c}\text { IFAT } \\
\text { Haemagglutination }\end{array}$ & $33.3 \%$ & 1983 & 36 \\
\hline $\begin{array}{l}\text { Pregnant women- } \\
\text { Military personnel }\end{array}$ & Blood & Rabat & ELISA & $27.4 \%$ & 1973 & 34 \\
\hline Pregnant women & Blood & Rabat & ELISA & $50.6 \%$ & 2017 & 41 \\
\hline Pregnant women & Blood & Casablanca & - & $51.5 \%$ & 1984 & 40 \\
\hline HIV patients & Blood & Marrakech & ELISA & $62.0 \%$ & 2012 & 53 \\
\hline Pregnant women & Blood & Fes & CMIA & $39.7 \%$ & 2017 & 45 \\
\hline Sheep & Blood & Marrakech & ELISA & $30.0 \%$ & 1990 & 47 \\
\hline Sheep & $\begin{array}{c}\text { Blood } \\
\text { Cerebral }\end{array}$ & Marrakech & $\begin{array}{l}\text { ELISA } \\
\text { Bioassay }\end{array}$ & $30.0 \%$ & 2004 & 48 \\
\hline $\begin{array}{l}\text { Sheep } \\
\text { Goats }\end{array}$ & Blood & $\begin{array}{l}\text { Northern } \\
\text { Middle atlas }\end{array}$ & ELISA & $\begin{array}{c}20.8 \% \\
\text { sheep } \\
8.5 \% \\
\text { goats }\end{array}$ & 2015 & 50 \\
\hline Cattle & Blood & $\begin{array}{l}\text { Meknes } \\
\text { Settat }\end{array}$ & Direct agglutination & $\begin{array}{l}7.5 \% \\
8.5 \%\end{array}$ & 2017 & 51 \\
\hline Environment & Soil & Marrakech & Microscope & $0.0 \%$ & 2020 & 52 \\
\hline
\end{tabular}

\section{CONCLUSION AND RECOMMENDATIONS}

This general review attempted to illustrates the fact that $T$. gondii holds high levels of significance within the public health spectrum both in Palestine and Morocco. Needless to mention, it is recognized as one of the most important parasites around the world. As already mentioned above, several studies have confirmed the phenomenon in which this parasite in fact exists among pregnant women. In Morocco, for instance, almost half of pregnant women who have been tested for toxoplasmosis indeed had been infected previously or currently are infected. In Palestine, the prevalence exists and is significant, though it is lower than the percentage in Morocco. While the few studies regarding the prevalence of this parasite among the livestock in both countries prove the existence of toxoplasmosis, they are still limited. They are limited given that none of the studies have addressed a clear clarification to the causes of this infection or even any prevention methods in both of the countries under examination. Another shortfall of the current studies concerning this parasite in Palestine and Morocco is the fact that the geographical area assessed is insufficient since most of the studies are constraint to certain places and cities. Certainly, both countries require to exert more surveillance efforts in investigating the existence of this parasite in the environment, soil, water, animals and poultry as well as vegetables and fruits. There was only one study associated with the occurrence of $T$. gondii in women who have undergone abortion in Palestine. Since this was only carried out in one city, Gaza, there needs to be more studies targeting other regions of Palestine. In contrast, studies concerning the prevalence of $T$. gondii among this specific segment of women are yet to be pursued in Morocco. Certainly, many more studies are still required to be performed in order to investigate the occurrence of congenital toxoplasma in both countries, as well as in patients with HIV covering other regions in Morocco. As for Palestine, there are no documented data regarding HIV. While many studies were carried out in both countries around the prevalence of $T$. gondii using serological methods, and yet since molecular studies are inadequate, molecular and genotyping studies are strongly encouraged and recommended for implementation and further investigative results.

\section{REFERENCES}

[1] Gunn, A., and Pitt, S. J. (2012). Parasitology: an integrated approach. John Wiley \& Sons.

[2] Bogitsh, B. J., Carter, C. E., and Oeltmann, T. N. (2018). Human parasitology. Academic Press.

[3] Maenz, M., Schlüter, D., Liesenfeld, O., Schares, G., Gross, U., and Pleyer, U. (2014). Ocular toxoplasmosis past, present and new aspects of an old disease. Progress in retinal and eye research, 39, 77-106.

[4] Robert-Gangneux, F., and Dardé, M. L. (2012). Epidemiology of and diagnostic strategies for toxoplasmosis. Clinical microbiology reviews, 25(2), 264-296. 
[5] Tenter, A. M., Heckeroth, A. R., and Weiss, L. M. (2000) Toxoplasma gondii: from animals to humans. International journal for parasitology, 30(12-13), 1217-1258.

[6] Dias, R. A. F., Navarro, I. T., Ruffolo, B. B., Bugni, F. M., Castro, M. V. D., andFreire, R. L. (2005). Toxoplasma gondii in fresh pork sausage and seroprevalence in butchers from factories in Londrina, Paraná State, Brazil. Revista do Instituto de Medicina Tropical de São Paulo, 47(4), 185-189.

[7] Scallan, Elaine, Robert M. Hoekstra, Frederick J. Angulo, Robert V. Tauxe, Marc-Alain Widdowson, Sharon L. Roy, Jeffery L. Jones, and Patricia M. Griffin. (2011). "Foodborne illness acquired in the United States-major pathogens." Emerging infectious diseases 17(1): 7 .

[8] Kapperud, G., Jenum, P. A., Stray-Pedersen, B., Melby, K. K., Eskild, A., and Eng, J. (1996). Risk factors for Toxoplasma gondi infection in pregnancy: results of a prospective case-control study in Norway. American journal of epidemiology, 144(4), 405-412.

[9] Cook, A. J. C., Richard Holliman, R. E. Gilbert, W. Buffolano, J. Zufferey, E. Petersen, P. A. Jenum, W. Foulon, A. E. Semprini, and D. T. Dunn. (2002). "Sources of toxoplasma infection in pregnant women: European multicentre case-control study Commentary: Congenital toxoplasmosis-further thought for food." Bmj 321, 7254: 142-147.

[10] Hill, D., and Dubey, J. P. (2002). Toxoplasma gondii: transmission, diagnosis and prevention. Clinical microbiology and infection, $8(10)$ 634-640.

[11] Al-Hindi, A., Madhon, M. J., Abo-Karsh, D. N., and Mansor, A. O. (2017). Toxoplasmosis Among Pregnant and Non-Pregnant Women Attending Al-Shifa Hospital In Gaza Strip, Palestine. British Journal of Medical and Health Research., 4, 9.

[12] Andreoletti, O., Budka, H., Buncic, S., Colin, P., Collins, D. J., and De Koeijer,(2007). A. Scientific opinion of the panel on biological hazards on a request from EFSA on surveillance and monitoring of Toxoplasma in humans, foods and animals. EFSA Journal, 5(83), 164.

[13] Scallan, E., Hoekstra, R. M., Mahon, B. E., Jones, T. F., andGriffin, P. M. (2015). An assessment of the human health impact of seven leading foodborne pathogens in the United States using disability adjusted life years. Epidemiology \& Infection, 143(13), 2795-2804.

[14] Havelaar AH, Haagsma JA, Mangen MJ, Kemmeren JM, Verhoef LP, Vijgen SM, Wilson M, Friesema IH, Kortbeek LM, van Duynhoven YT, and van Pelt W. (2012). Disease burden o foodborne pathogens in the Netherlands, 2009. International journal of food microbiology, 156(3), 231-238.

[15] FAO, W. (2014). Multicriteria-based ranking for risk management of food-borne parasites. Rome: Food and Agriculture Organization.

[16] World

Health

Organizationhttp://www.euro.who.int/_data/assets/pdf_file/0011/29 4599/Factsheet-Toxoplasmosis-en.pdf?ua=1 [ Accessed in 8 January 2019].

[17] World Health Organizationhttp://www.euro.who.int/en/healthtopics/disease-prevention/food-safety/news/news/2015/12/morethan-23-million-people-in-the-who-european-region-fall-ill-fromunsafe-food-every-year [Accessed in 26 February 2019].

[18] Nijem, K.I., and Al Amleh, S. (2009). Seroprevalence and associated risk factors of toxoplasmosis in pregnant women in Hebron district Palestine. The Eastern Mediterranean Health Journal is a healthcare journal, 155 ,

1278 1284.https://apps.who.int/iris/handle/10665/117759.

[19] Al-Hindi, A.I., and Lubbad, A.H. (2009). Seroprevalence of toxoplasmosis among Palestinian aborted women in Gaza. Annals of Alquds medicine. 5, 39-47.

[20] Al-Sheyab, N. A., Obaidat, M. M., BANI SALMAN, A. E., and Lafi, S. Q. (2015). Toxoplasmosis-related knowledge and preventive practices among undergraduate female students in Jordan. Journal of food protection, 78(6), 1161-1166.

[21] Al-Hindi, A. A., Al-Helou, T., and Al-Helou, Y. (2010). Seroprevalence of Toxoplasma gondii, cytomegalovirus, rubella virus and Chlamydia trachomatis among infertile women attending in vitro fertilization center, Gaza strip, Palestine. Journal of the Egyptian Society of Parasitology, 40(2), 451-458.

[22] Al-Jarousha A. M. (2012). Toxoplasma gondii infection among pregnant women in Gaza strip. Annals of Alquds Medicine.8,14-24. Available

from:https://annalqudsmed.files.wordpress.com/2012/03/toxoplasmo sis-gp.pdf.

[23] Sweileh, W.M., Jodeh, D.S., andIsra'S, R. (2017). Toxoplasmosisrelated knowledge and preventive practices among undergraduate female students at An-Najah National University, Palestine. IUG Journal of Natural Studies.2, 5-3.
[24] Nigem, M.M.M. (2009). Toxoplasma gondii infection among university female students and some domestic animals in Gaza Strip. (Doctoral dissertation, Al-Azhar University-Gaza).

[25] OTHMAN, R. A., and ALZUHEIR, I. (2014). Seroprevalence of Toxoplasma gondii in goats in two districts in Northern Palestine. Walailak Journal of Science and Technology (WJST), 11(1), 63-67.

[26] Othman, R. A., Jalboush, N. A., and Alzuheir, I. M. (2017). Seroprevalence of Toxoplasma gondii in sheep in northern Palestine and Jordan valley. Indian Journal of Veterinary Research (The), 26(2), 17-20.

[27] Al-Hindi, A. I., Abu-Draz, M., El-Zenati, A., Ali, A. A., and Dagga, A. A. (2019). Occurrence of Toxoplasmosis and other intestinal parasites among stray Cats in Khanyounis Governorate, Palestine. IUG Journal of Natural Studies, 27(2).

[28] Al-Shawa, R. M., andS. N. Mwafy. (2017). The enteroparasitic contamination of commercial vegetables in Gaza Governorates.Journal of Infection in Developing Countries.11,62-66.

[29] Al-Hindi, A. I., Elmanama, A. A., and Khalaf, S. (2016). Prevalence of intestinal parasites and microbial contamination in common edible vegetables used in Gaza Governorate, Palestine. Journal of Food Safety and Hygiene, 2(1/2), 21-25.

[30] Hilles, A. H., Al-Hindi, A. I., and Abu Safieh, Y. A. (2013). Is Gaza sandy shoreline region contaminated with human gastrointestinal parasites? Is Gaza sandy shoreline region contaminated with human gastrointestinal parasites?, 6(3).

[31] Dardona, Z., Boussaa, S., Al-Hindi, A., Aboumezzough, A., and Hafidi, M. (2020). The occurrence of Toxoplasma gondii on raw leafy vegetables in Gaza-Palestine. Journal of Food Protection.

[32] Le Viguelloux J, and Epardeau BMed Trop (Mars). (1969). Use of indirect immunofluorescence reactions in epidemiologic studies. A Preliminary study: toxoplasmosis. 291, 76-83.

[33] Mekouar A. (1972). Contribution of the epidemiology of toxoplasmosis, serology of toxoplasmosis in Morocco. Ph.D thesis Faculty of Medicine and Pharmacy, Bordeaux $\Pi$ University, France.

[34] Nejmi S, andAlami S. (1973). Étude immunologique de la toxoplasmose dans la population marocainepar la réactiond'immunofluorescenceindirecte (1026 sérums). Maroc Médical.572, 561-568.

[35] El Mansouri B, Rhajaoui M, Sebti F, Amarir F, Laboudi M, Bchitou R, Hamad M, andLyagoubi M. (2007). Seroprevalence of toxoplasmosis in pregnant women in Rabat, Morocco. Bull Soc PatholExot.100 (4), 289-90.

[36] Biava, M. F., Jana, M., El Mansouri, A., and Percebois, G. (1983) Etude séro-épidémiologique de la toxoplasmose à Marrakech (Maroc). Médecine et Maladies infectieuses, 13(9), 503-506.

[37] Errifaiy, H., and Moutaj, R. (2014). Evaluation des connaissances, des comportements et des statutsimmunitaires des femmes enceintes par rapport à la toxoplasmose: Enquêteépidémiologique dans la région Essaouira-Safi. Consommation, 42(5), 0-009.

[38] Barkat, A., Kabiri, M., Tligui, H., and Bouazzaoui, L. N. (2010). 976 Seroprevalence of Toxoplasmosis in Morocco. Pediatric Research, 68(1), 486-487.

[39] Laboudi, M., an Sadak, A. (2017). Serodiagnosis of Toxoplasmosis the effect of measurement of IgG avidity in pregnant women in Rabat in Morocco. Acta tropica, 172, 139-142.

[40] Laboudi, M. (2017). Review of toxoplasmosis in Morocco: seroprevalence and risk factors for toxoplasma infection among pregnant women and HIV-infected patients. The Pan African medical journal, 2.7.

[41] Laboudi, M., El Mansouri, B., Sebti, F., Amarir, F., Coppieters, Y. and Rhajaoui, M. (2009). Facteurs de risqué d'une sérologie toxoplasmique positive chez la femme enceinte au Maroc. Parasite, 16(1), 71-72.

[42] Laboudi, M., El Mansouri, B., and Rhajaoui, M. (2014). The role of the parity and the age in acquisition of Toxoplasmosis among pregnant women in Rabat-Morocco. International Journal of Innovation and Applied Studies, 6(3), 488.

[43] Ouzennou, N., Boussaa, S., Alla, S. B., and Boumezzough, A. (2019). Observational study to assess pregnant women's knowledge and behaviour related to toxoplasmosis in Essaouira province, Morocco. Asian Pacific Journal of Tropical Medicine, 12(2), 87.

[44] Tlamcani, Z., Yahyaoui, G., and Mahmoud, M. (2017). Prevalence of immunity to toxoplasmosis among pregnant women in University Hospital center Hassan II of FEZ city (Morocco). Acta Medica International, 4(1), 43

[45] AO. Bureau sous-régional de la FAO pour l'Afrique du Nord, Les maladies animal estransfrontalières:les maladies à fort impact socioéconomique.Lettred'Information,N3,3ème trimester Available. 2013. Athttp://www.fao.org/3/a-i4644f.pdf. 
[46] Benkirane, A., Jabli, N., and Rodolakis, A. (1990). Frequency of abortion and seroprevalence of the principal diseases causing ovine infectious abortion in the area of Rabat (Morocco). Annales de recherchesveterinaires. Annals of veterinary research, 21(4), $267-$ 273.

[47] Belbacha, I., J. Hafid, R. Tran Manh Sung, P. Flori, H. Raberin, R. Aboufatima, A. Regragui, A. Dalal, and A. Chait (2004). Toxoplasma gondii: taux de portage chez les ovins de la région de Marrakech (Mnabha). Schweizer ArchivfürTierheilkunde, 146(12), 561-564.

[48] Sawadogo, P., Hafid, J., Bellete, B., Sung, R.T.M., Chakdi, M., Flori, P., Raberin, H., Hamouni, I.B., Chait, A., and Dalal, A., (2005). Seroprevalence of $T$. gondii in sheep from Marrakech, Morocco. Veterinary Parasitology, 130(1-2), 89-92.

[49] Benkirane, A., Essamkaoui, S., El Idrissi, A., Lucchese, L., and Natale, A. (2015). A sero-survey of major infectious causes of abortion in small ruminants in Morocco. Veterinaria Italiana. 51(1), 25-30.

[50] Essayagh, M., Essayagh, T., Khallayoune, K., Essayagh, S., and Lmimouni, B. (2017). Seroprevalence of Toxoplasma gondii in Ruminants in Morocco. Veterinary Research. 2017, 10(1), 1-5.

[51] Berrouch S, Ajgoune H, Hoummadi L, Amraouza Y, Maarouf A, Boularbah A, Admou B, and Hafid J. (2020). First Investigation of The Occurrence of Toxoplasma gondii Oocysts in Urban Soil in Marrakesh, Morocco. Comparative Parasitology, 87(1), 99-102.

[52] Addebbous A, Adarmouch L, Tali A, Laboudi M, Amine M, Aajly L, Rhajaoui M, Chabaa L, and Zougaghi L. (2012). IgG antiToxoplasma antibodies among asymptomatic HIV-infected patients in Marrakesh-Morocco. Acta tropica, 123(1), 49-52.

[53] Global Health,Division of Parasitic Diseases and Malaria. 2017. https://www.cdc.gov/dpdx/toxoplasmosis/index.html. [Accessed in 6 Jan 2019]. 